\title{
Desmin Distribution in the Cardiac Outflow Tract of the Chick Embryo during Aortico-pulmonary Septation
}

\author{
Hiroshi SumidA ${ }^{1}$, Harukazu NAKAmura ${ }^{2}$, Naotaka AKImoto ${ }^{1}$, Naomasa OKAmoto $^{1}$ \\ and Yukio SATOW ${ }^{1}$
}

Department of Geneticopathology (Prof. Y. SATow) ${ }^{1}$, Research Institute for Nuclear Medicine and Biology, and Department of Anatomy², Hiroshima University School of Medicine, Hiroshima, Japan

Received August 17, 1987

\begin{abstract}
Summary. The appearance and distribution of desmin, a muscle type intermediate filament, was examined in the truncus arteriosus of the chick embryonic heart during AP septation by an indirect immunofluorescence method. Prior to septation, on the 4 th day of incubation, staining with antidesmin antibody was observed in the AP septum anlagen in the distal truncus. No staining with the antibody was detected in the developing tunica media of the great arteries in the distal truncus at this stage. During septation, on the 5th day of incubation, intense staining with the antidesmin antibody was observed in the cell condensation of the AP septum. In the 6-day-old embryo, the staining in the AP septum was reduced, but fluorescence by staining with the antibody was observed in the developing tunica media. No fluorescence was detected in other mesenchymal cells in the truncal swellings.

Because of the time of appearance and the localization of antidesmin reactivity in the developing AP septum, it is suggested that muscle-type cells exist in the AP septum, and that these cells may perform an important function in septation.
\end{abstract}

During the development of the heart in higher vertebrates, the initial single arterial pole, the truncus arteriosus, is divided into two major vessels: the aorta and the pulmonary artery. Because truncal anomaly is one of the most frequently occurring congenital cardiac defects, much attention has been paid to the morphogenesis of the outflow tract (Los, 1978; OKAMOTO, 1980; THOMPSON et al., 1983, 1985).

Before septation, the anlagen of the aortico-pulmonary (AP) septum appear as mesenchymal condensations in the distal part of the right and left truncal swellings. While the right and left swellings fuse with each other from a distal to proximal direction against the blood flow, the AP septum comes into recognition as a cell condensation between the aortic and pulmonary lumens (VAN MieloP, 1969; LAANE, 1978, 1979).

Recently, phalloidin staining has demonstrated organized actin bundles with consistent orientation in the AP septum (SUMIDA et al., 1985a, b). Electron microscopy has further demonstrated that some of the cells within the AP septum have stress fiber-like bundles. It has been suggested that these cells play an important role in the division of the truncus arteriosus (THOMPSON et al., 1983, 1984, 1985). However, the characteristics of the cells with microfilaments within the AP septum still remain unclear. Thus, the following questions were raised: 1) Are the cells containing actin bundles within the AP septum muscular in nature? 2) Are these cells precursors of the tunica media of the great arteries? 
To answer these questions, we examined the appearance and distribution of desmin, a muscle-type intermediate filament (LAZARIDES, 1980, 1982), in the chick outflow tract using an immunohistochemical method.

\section{MATERIALS AND METHODS}

Fertilized White Leghorn chicken eggs were incubated at $38^{\circ} \mathrm{C}$ in a humidified atmosphere. The embryos were fixed at either 4,5 or 6 days of incubation in $4 \%$ formaldehyde in $0.1 \mathrm{M}$ phosphate buffer $\mathrm{pH} 7.4$ for $4 \mathrm{hrs}$ at room temperature. After staging according to HAMBURGER and HAMILTON (1951), the specimens were dehydrated with a graded series of ethanol and embedded in paraffin.

\section{Immunofluorescent staining}

Deparaffinized $6 \mu \mathrm{m}$ thick sections were incubated in $0.1 \%$ trypsin in $0.1 \% \mathrm{CaCl}_{2}$ for 30 $\min$ at $37^{\circ} \mathrm{C}$. This treatment has been reported to increase sensitivity for the detection of antigens in tissues embedded in paraffin (HAUTZER et al., 1980). The following procedures were performed at room temperature: after rinsing in phosphate buffered saline (PBS), the sections were blocked with $20 \%$ normal goat serum in PBS for 20-30 min to avoid non-specific staining. This procedure was followed by incubation for 60 min with antidesmin rabbit IgG, diluted 50 times, raised against desmin from chicken gizzard (Bio-Science Products, Switzerland). For the control, non-immune rabbit IgG was employed in place of the antibody.

After rinsing in PBS, the sections were incubated with FITC-labeled goat antirabbit IgG (affinity purified, Bio-Yeda, or Tago, USA) for $30 \mathrm{~min}$. The sections were rinsed in PBS, and mounted with glycerol-PBS $(1: 1)$ solution, and photographed under a fluorescence microscope (Olympus, BH2-RFK) with a B460 filter. The control specimens showed a negligible degree of fluorescence.

After observation under a fluorescence microscope, the coverslips were removed in PBS, and the sections were stained with hematoxylin and eosin.

\section{RESULTS}

In the present study, we modified Los's terminology (1978) concerning the developing heart as follows: "Truncus arteriosus" indicates the whole arterial pole, "distal truncus," the area including the "aortic sac," and "proximal truncus," the area including the "conus cordis" or "bulbus" or "infundibulum," The "distal truncus" denotes the region of the aortic arches of the embryo at a later stage. "AP septum anlagen" signifies condensed cell masses in the truncal swellings.

In the four-day-old chick embryo (stages 22-24), the truncus arteriosus was not divided, and a single lumen was seen in cross sections (Fig. 1a). The right and left truncal swellings were developing between the endocardium and the myocardium of the truncus. On both the left and right swellings, the anlagen of the AP septum were recognizable as condensed cell masses (Fig. 1a). A fluorescence micrograph (Fig. 1b) showed that these cell masses had reacted to antidesmin. No fluorescence was seen in the other cell group in the swellings.

At this stage, the cardiac muscle which strongly reacted to the antidesmin antibody surrounded the truncus arteriosus (Fig. 1a). The atrium reacted strongly to 

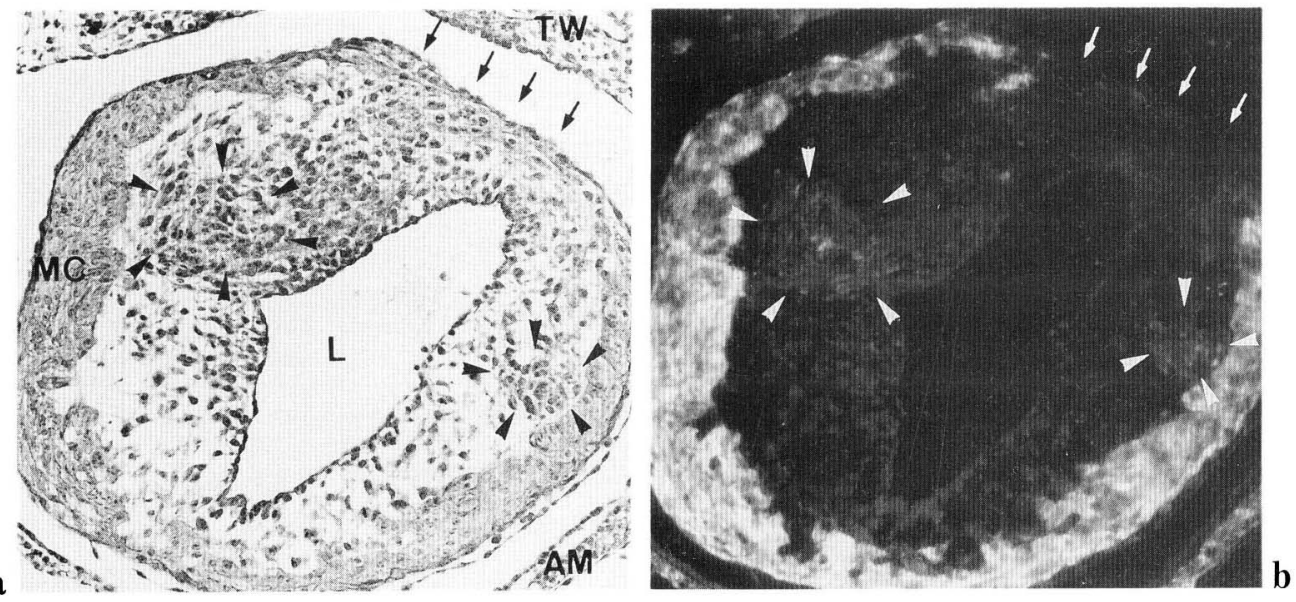

Fig. 1. A cross section of the distal truncus of the 4-day-old chick embryo. a. Hematoxylin and eosin staining, b. Immunofluorescence micrograph of the same field as in a. The anlagen of the AP septum are seen as cellular condensations (surrounded by arrowheads in a). Reactivity of the antidesmin antibody is recognizable in the region corresponding to the anlagen of the AP septum (b). The myocardium surrounding the atrium $(A M)$ and truncus arteriosus $(M C)$ shows intense staining. No fluorescence is seen in the developing tunica media (arrows). $L$ lumen of the truncus, $T W$ thoracic wall. $\times 400$

the antidesmin antibody. In a region which lacked the myocardium in the distal truncus, no fluorescence was observed (Fig. 1a, b). Hematoxylin and eosin staining showed thas the tissue of this region was the tunica media of the great arteries.

In the five-day-old chick embryo (stages 25-27), the right and left truncal swellings were in the process of fusing from distal to proximal, dividing the lumen into the aortic and pulmonary lumens. The AP septum appeared as a dense cell mass in the sparsely scattered mesenchymal cells of the swellings (Fig. 2c). This cell mass strongly reacted to the antidesmin antibody, other mesenchymal cells in the swellings not being stained with the antibody (Fig. 2d).

The tunica media of the great arteries was developing toward the proximal truncus (Fig. 2c). In the distal truncus, the arteries were completely divided into the aorta and pulmonary artery, and a condensed cell layer of the tunica media had developed around each lumens (Fig. 2a). At this stage, however, the developing tunica media in the distal truncus was not stained with the antidesmin antibody (Fig. 2b).

The myocardium surrounding the truncus arteriosus and the atrium strongly reacted to the antidesmin antibody, but the thoracic wall and the epicardium failed to do so (Fig. 2c, d).

In the six-day-old chick embryo (stages 28-30), the developing tunica media appeared as a concentric layer around the distal and proximal arterial lumens (Fig. 3a, c); at this stage the tunica media of the distal truncus was not stained with the antidesmin antibody (Fig. 3b).

The AP septum still remained a condensed cell mass (Fig. 3a, c), and reacted to the antidesmin antibody, though reactivity was weaker than that seen on the previous day.

The myocardium reacted strongly to the antibody. 

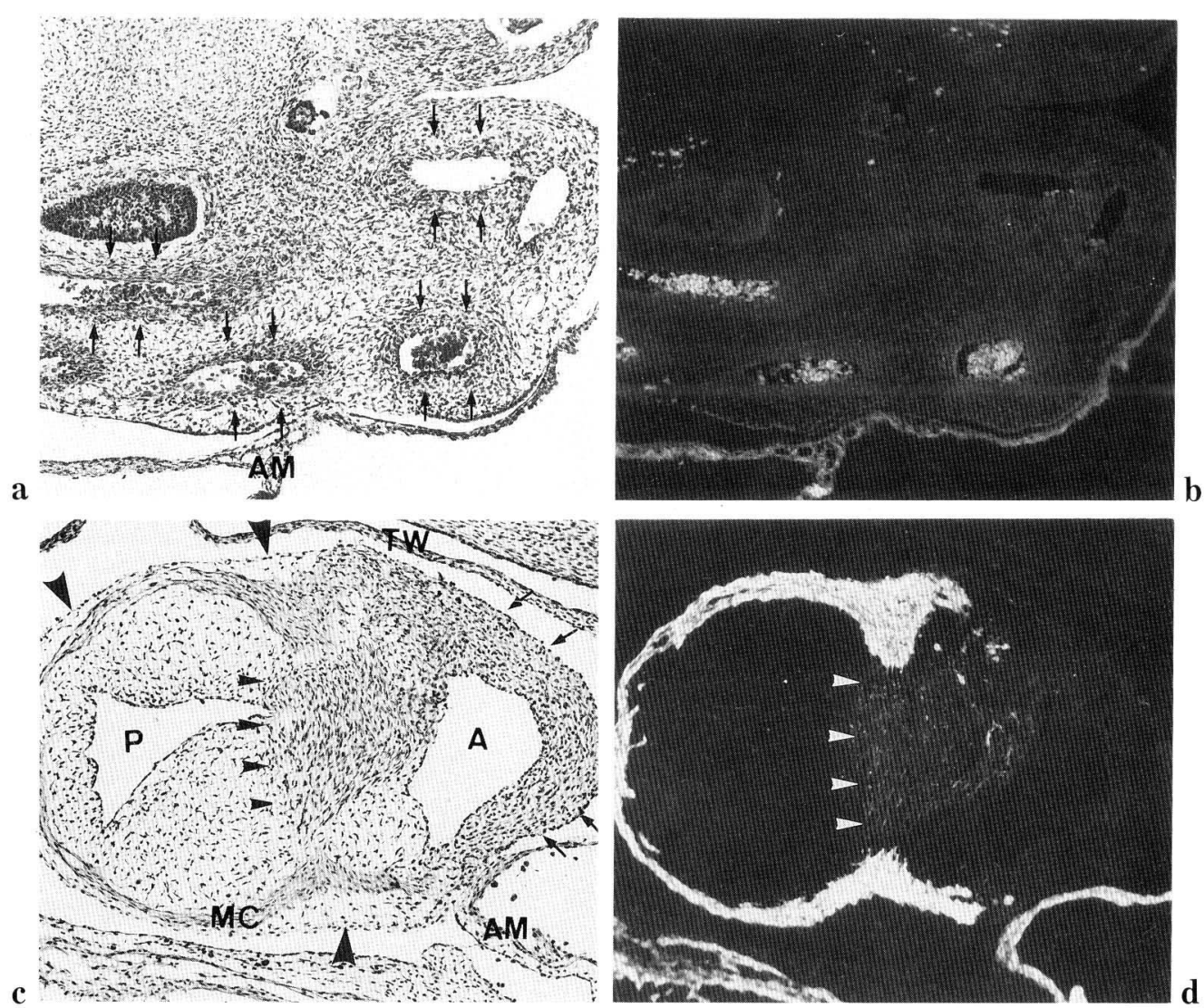

Fig. 2. Cross sections of the distal $(\mathbf{a}, \mathbf{b})$ and the proximal truncus $(\mathbf{c}, \mathbf{d})$ in the 5 -day-old chick embryo. a and c. Hematoxylin and eosin staining. b and $\mathbf{d}$. Immunofluorescence micrographs of the same fields as in a and $\mathbf{c}$, respectively. The section $(\mathbf{c}, \mathbf{d})$ is just distal to the division of the truncus into the aortic and pulmonary lumens. The truncus more proximal to the level of $\mathbf{c}$ is not divided. No fluorescence is seen in the developing tunica media (arrows) nor in the epicardium (large arrowheads). In the AP septum (arrowheads), the reactivity of antidesmin is apparent. The myocardium surrounding the atrium $(A M)$ and truncus arteriosus $(M C)$ shows intense staining. $A$ aortic lumen, $P$ pulmonary lumen, $T W$ thoracic wall. $\times 200$

\section{DISCUSSION}

Our findings in this study are summarized as follows: 1) The cellular condensation in the AP septum and its anlagen reacted to the antibody raised against desmin, but the other cells in the truncal swellings did not;2) the developing tunica media of the great arteries was not stained with the antibody until the 6th day of inclbation.

Prior to septation, the anlagen of the AP septum appear as condensed cell columns in the swellings across the truncus arteriosus (see Fig. 1) (LAANE, 1978; Los, 1978). Our first finding is that the cells in the anlagen of the AP septum are immunohistochemically desmin positive. As desmin is found predominantly in muscle cells, it has been thought that desmin is characteristically expressed in muscle cells with the exception 

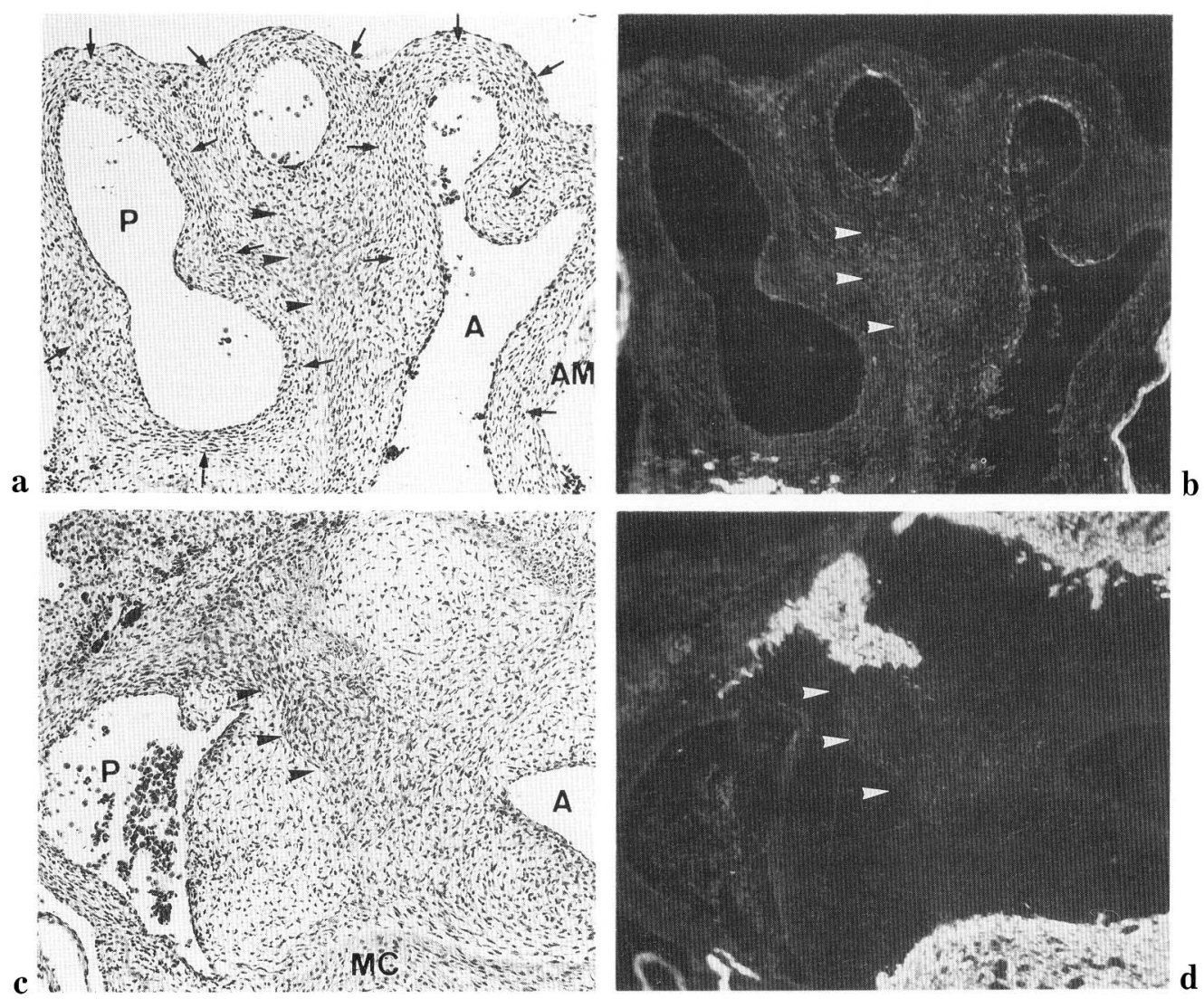

Fig. 3. Cross sections of the distal $(\mathbf{a}, \mathbf{b})$ and proximal truncus $(\mathbf{c}, \mathbf{d})$ in the 6-day-old chick embryo. $\mathbf{a}$ and $\mathbf{c}$. Hematoxylin and eosin staining. $\mathbf{b}$ and $\mathbf{d}$. Immunofluorescence micrographs of the same fields as in a and $\mathbf{c}$, respectively. In the developing tunica media (arrows) of the distal truncus, weak reactivity of the antidesmin antibody is recognizable. In the AP septum (arrowheads), reactivity to the antidesmin antibody is positive but weaker than that seen on the previous day. $A$ aortic lumen, $P$ pulmonary lumen, $A M$ myocardium surrounding the atrium, $M C$ myocardium surrounding the truncus arteriosus. $\times 200$

of some cells (LAZARIDES, 1982). Therefore, the cells within the AP septum and its anlage are referred to as muscle-type cells.

Condensed cells within the AP septum were believed to derive from the extracardiac area (VAN MIELOP, 1969). Recent studies have shown that these cells derive from the neural crest (KIRBY et al., 1983, 1985; AKIMOTO et al., 1986). On the other hand, loose mesenchymal cells in the truncal swellings derive from the endocardium (MARKWALD et al., 1975, 1977; FitzHARRIS, 1981; FitzHARRIS and MARKWALD, 1982). Thus, the appearance of the desmin positive and negative cells in the truncal swellings may reflect their derivation.

The AP septum develops from the distal truncus toward the ventricles. Similarly, the tunica media of the great arteries develops in a distal to proximal direction (Fitzharris et al., 1979; THOMPSON and FitzhARRIs, 1979). The neural crest cells migrate into the tunica media of the distal truncus as well as into the AP septum, but 
these cells do not migrate into the tunica media of the proximal truncus at the level of the proximal region of the AP septum (AKIMOTO et al, 1986). This finding suggests that the cells in the AP septum and in the tunica media of the great arteries are of different origin. Furthermore, the developing tunica media of the truncus did not react to the antidesmin antibody at the stage when the AP septum was intensely stained with the antibody (see Fig. 1 and 2). The tunica media of the great arteries was stained with the antidesmin antibody in the 6-day-old chick embryo. It was at this stage that, contrarily, staining in the AP septum was decreasing. From these results, it is suggested that the muscle-type cells in the AP septum are neither developing smooth muscle cells nor their precursor cells of the tunica media of the great arteries.

ICARDO (1985) reported that the AP septum in the chick embryo was rich in fibronectin during septation. After septation in the 6-day-old chick embryo, fibronectin reactivity within the AP septum decreased. We demonstrated that the reaction to the antidesmin in the AP septum decreased in the 6-day-old chick embryo. It was shown that F-actin bundles with consistent orientation were localized in the AP septum (SumIDA et al., 1985a, b). Although a close association between fibronectin and actin fiber has been described (HYNES 1981), the relationship between fibronectin and desmin is still unclear. Elucidation of their relationship will be necessary.

In the truncal swellings, the muscle-type cells already appeared within the AP septum anlagen prior to septation. This finding suggests that the muscle-type cells may functionally contribute to the division of the truncus arteriosus. The muscle-type cells might have both mechanical strength and contractile ability. This characteristic of the muscle type cells may be required in order to divide the single lumen into the aortic and pulmonary lumens against the direction of the blood flow.

Acknowledgments. We would like to thank Mr. S. YAMADA for technical assistance and Mrs. Y. MATSUI for secretarial assistance. We also wish to thank Prof. K. KATAOKA (Anatomy) for helpful comment.

\section{REFERENCES}

Akimoto, N., Y. Satow, L. Y. Lee, H. Sumida, H. Nakamura and N. Okamoto: Neural crest cells and division of conotruncus in birds (In Japanese). Proc. Hiroshima Univ. RINMB 27: 211-223 (1986).

Fitzharris, T. P.: Origin and migration of cushion tissue in the developing heart. Scanning Electron Microsc. 1981/II: 254-260 (1981).

Fitzharris, T. P. and R. R. Markwald: Cellular migration through the cardiac jelly matrix: A stereoanalysis by high-voltage electron microscopy. Devel. Biol. 92: 315-329 (1982).

Fitzharris, T. P., R. P. Thompson and R. R. Markwald: Matrical ordering in the morphogenesis of tunica media. Texas Rep. Biol. Med. 39: 287-304 (1979).

Hamburger, V. and H. L. Hamilton: A series of normal stages in the development of the chick embryo. J. Morphol. 88: 49-92 (1951).

Hautzer, N. W., J. F. Wittkuhn and W. T. Elliott McCaughey: Trypsin diggestion in immunoperoxidase staining. J. Histochem. Cytochem. 28: 52-53 (1980).

Hynes, R. O.: Fibronectin and its relation to cellular structure and behavior. In: (ed. by) E. D. Hay: Cell biololy of extracellular matrix. Plenum, New York, 1981 (p. 295-334). 
Icardo, J. M.: Distribution of fibronectin during the morphogenesis of the truncus. Anat. Embryol. 171: 193-200 (1985).

Kirby, M. L., T. F. Gale and D. E. Stewart: Neural crest cells contribute to normal aorticopulmonary septation. Science 220: 1059-1061 (1983).

Kirby, M. L., K. L. Turnage, III and B. M. Hays: Characterization of conotruncal malformations following ablation of "cardiac" neural crest. Anat. Rec. 213: 87-93 (1985).

Laane, H-M.: The septation of the arterial pole of the heart in the chick embryo. II. Development of the truncus arteriosus of the heart of chick embryos from 4 to 5 days of incubation. Acta morphol. neel.-scand. 16: 29-53 (1978).

: The septation of the arterial pole of the heart in the chick embryo. III. Development of the truncus arteriosus of the heart of chick embryos from $51 / 2$ to 7 days of incubation. Acta morphol. neel.-scand. 17: 1-20 (1979).

Lazarides, E.: Intermediate filaments as mechanical integrators of cellular space. Nature 283: 249-256 (1980).

: Intermediate filaments: A chemically heterogeneous, developmentally regulated class of proteins. Ann. Rev. Biochem. 51: 219-250 (1982).

Los, J. A.: Cardiac septation and development of the aorta, pulmonary trunk, and pulmonary veins: Previous work in the light of recent observations. Birth Defects: orig. Art. Ser. 14 (7): 109-138 (1978).

Markwald, R. R., T. P. Fitzharris and W. N. Adams Smith: Structural analysis of endocardial cytodifferentiation. Devel. Biol. 42: 160-180 (1975).

Markwald, R. R., T. P. Fitzharris and F. J. Manasek: Structural development of endocardial cushions. Amer. J. Anat. 148: 85-120 (1977).

Okamoto, N.: Congenital anomalies of the heart: Embryologic, morphologic and experimental teratology. Igaku-Shoin, Tokyo, 1980 (p. 22-58).

Sumida, H., R. A. Ashcraft, Jr. and R. P. Thompson: Cytoplasmic stress fibers in the developing heart. Bull. South Carolina Acad. Sci. 47: 167 (1985a). oping heart. Circulation 72: III-95 (1985b).

Thompson, R. P. and T. P. Fitzharris: Morphogenesis of the truncus arteriosus of the chick embryo heart: Tissue reorganization during septation. Amer. J. Anat. 156: 251-264 (1979).

Thompson, R. P., Y-M. M. Wong and T. P. Fitzharris: A computer graphic study of cardiac truncal septation. Anat. Rec. 206: 207-214 (1983).

- : Patterns of tensile stress in the developing cardiac truncus. In: (ed. by) J. J. Nora and A. Takao: Congenital heart disease: Cause and processes. Futura, Mount Kisco, New York, 1984 (p. 387-400).

Thompson R. P., H. Sumida, V. Abercrombie, Y. Satow, T. P. Fitzharris and N. Okamoto: Morphogenesis of human cardiac outflow. Anat. Rec. 213: 578-586 (1985).

Van Mielop, L. S. H.: Embryology, Section III. In: (ed. by) F. H. Netter and F. F. Yonkman: The Ciba collection of medical illustration, Vol. 5. Ciba Foundation, New York, 1969 (p. 119-123).

隅田寛

于 734 広島市南区霞 $1-2-3$

広島大学原爆放射能医学研究所

遗伝・優生学部門
Hiroshi SUmidA

Department of Geneticopathology

Research Institute for Nuclear Medicene and Biology

Hiroshima University School of Medicine

1-2-3 Kasumi, Minami-ku Hiroshima, 734 Japan 